Joseph D. Tobias MD, Gail E. Rasmussen MD, George W. Holcomb III MD, John W. Brock III MD, Walter M. Morgan III MD

\title{
Continuous caudal anaesthesia with chloroprocaine as an adjunct to general anaesthesia in neonates
}

Purpose: The authors prospectively evaluated the use of a continuous caudal epidural infusion of chloroprocaine as an adjunct to general anaesthesia during intra-abdominal surgery in neonates.

Clinical features: The technique was used in 25 neonates ranging in age from 1 to 28 days and in weight from 2.2 to 4.9 $\mathrm{kg}$. Following anaesthetic induction and tracheal intubation, an initial bolus dose of chloroprocaine $3 \%$ (l or $1.5 \mathrm{ml} \cdot \mathrm{kg}^{-1}$ ) was followed by a continuous infusion of $l$ or $1.5 \mathrm{ml} \cdot \mathrm{kg}^{-1} \cdot \mathrm{hr}^{-1}$ administered through a caudal epidural catheter. No parenteral opioids were administered. The duration of the surgical procedures varied from one hour five minutes to three hours 15 min. The first three neonates received a bolus dose of 1.0

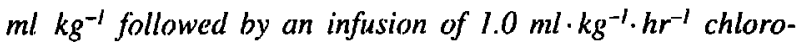
procaine $3 \%$. These three neonates required an additional bolus dose followed by an increase in the infusion to 1.5 $\mathrm{ml} \cdot \mathrm{kg}^{-1} \cdot \mathrm{hr}^{-1}$ to provide surgical anaesthesia. Adequate intraoperative anaesthesia was achieved in all 25 neonates with an infusion of $1.5 \mathrm{ml} \cdot \mathrm{kg}^{-1} \cdot \mathrm{hr}^{-1}$ of chloroprocaine $3 \%$. This was evidenced by a lack of haemodynamic response to surgical manipulation. No neonate required more than $0.2 \%$ isoflurane or $70 \%$ nitrous oxide in oxygen. No episodes of haemodynamic instability (decreased blood pressure/bradycardia) related

\section{Key words}

ANAESTHESIA: paediatric;

ANAESTHETICS, LOCAL: chloroprocaine;

ANAESTHESIA, REGIONAL: caudal epidural block.

From the Departments of Anethesiology and Pediatrics, the Division of Pediatric Critical Care/Anesthesia, the University of Missouri, Columbia, Missouri and the Departments of Anesthesiology, Pediatrics, Surgery, and Urology, Vanderbilt University, Nashville, Tennessee.

Address correspondence to: Dr. Joseph D. Tobias, Director, Pediatric Critical Care, The University of Missouri, Department of Child Health, M658 Health Sciences Center, One Hospital Drive, Columbia, Missouri 65212.

Accepted for publication 28th September, 1995. to the caudal epidural anaesthesia were noted. Twenty-three of 25 of the neonates' tracheas were extubated immediately (within 10 minutes) following the surgical procedure.

Conclusions: Caudal anaesthesia with a continuous infusion of chloroprocaine can be used as an adjunct to general anaesthesia during abdominal surgery in neonates. Our initial experience suggests that the combined technique may eliminate the need for parenteral opioids and limit the intraoperative requirements for inhalational anaesthetic agents.

Objectif: Les auteurs évaluent prospectivement l'utilisation d'une perfusion épidurale caudale continue de chlorprocaïne comme anesthésie d'appoint à la générale pendant la chirurgie abdominale du nouveau-né.

Eléments cliniques: Cette technique a été utilisée chez 25 nouveau-nés agés 1 à 28 jours et pesant de 2,2 à $4,9 \mathrm{~kg}$. Après. l'induction de l'anesthésie et l'intubation endotrachéale, une premier bolus de chloroprocaïne $3 \%\left(1,0\right.$ ou $\left.1,5 \mathrm{ml} \cdot \mathrm{kg}^{-1}\right)$ a été suivi d'une perfusion continue de 1,0 ou $1,5 \mathrm{ml} \cdot \mathrm{kg}^{-1} \cdot \mathrm{h}^{-1}$ administrée par une cathéter épidural caudal. On n'a pas administré de morphiniques parentéraux. La durée des interventions a varié de une heure cinq minutes à trois heures cinq minutes. Les trois premiers nouveau-nés ont reçu un bolus de $1.0 \mathrm{ml} \cdot \mathrm{kg}^{-1}$ suivi par une perfusion de $1,0 \mathrm{ml} \cdot \mathrm{kg}^{-1} \cdot \mathrm{h}^{-1}$ de chloroprocaïne 3\%. Ces trois nouveau-nés ont eu besoin d'une dose additionnelle en bolus suivie d'une augmentation de la perfusion à $1.5 \mathrm{ml} \cdot \mathrm{kg}^{-1} \cdot \mathrm{h}^{-1}$ pour obtenir une anesthésié chirurgicale. Une anesthésie peropératoire adéquate a été obtenue chez les 25 nouveau-nés avec une perfusion de 1.5 $\mathrm{ml} \cdot \mathrm{kg}^{-1} \cdot \mathrm{h}^{-1}$ de chloroprocaïne $3 \%$. Ceci a été confirmé par l'absence de réponse hémodynamique à la manipulation chirurgicale. Aucun des nouveau-nés n'a eu besoin de plus de $0,2 \%$ d'isoflurane ou de plus de $70 \%$ de protoxyde d'azote en oxygène. On n'a pas constaté d'instabilité hémodynamique (baisse de pression artérielle/bradycardie) en relation avec l'anesthésie caudale. Vingt-trois des 25 patients ont été extubés immédiatement (en moins de 10 minutes) après la chirurgie.

Conclusion: L'anesthésie caudale avec une perfusion de chloroprocaïne peut être utilisée comme appoint à 
l'anesthésie générale pendant la chirurgie abdominale chez le nouveau-né. Notre expérience initiale suggère que cette combinaison de techniques peut éliminer les besoins de morphiniques parentéraux et limiter les besoins peropératoires d'agents anesthésiques inhalatoires.

Regional anaesthetic techniques such as caudal epidural block have gained acceptance as a means of providing postoperative analgesia in children. ${ }^{1,2}$ Aside from this indication, regional techniques such as caudal epidural or spinal anaesthesia may be used in place of general anaesthesia in high risk neonates and infants. ${ }^{3.4}$ Benefits of such techniques include the avoidance of general anaesthesia and perhaps eliminating the risks of postoperative complications including apnoea, respiratory failure, and post-intubation croup.

While the use of combined techniques (general anaesthesia with intraoperative regional anaesthesia) is common practice in adults, its use in paediatric anaesthesia is limited. In addition to the provision of postoperative analgesia, several other benefits have been suggested for a combined technique such as avoiding the use of systemic opioids, blunting the post-surgical stress response, ${ }^{5}$ and decreasing the intraoperative requirements for inhalational agents. We present our initial experience in neonates with a combined general/caudal epidural anaesthetic technique with a continuous infusion of chloroprocaine.

\section{Methods}

\section{Anesthetic technique}

Before the procedure, risks were discussed and informed consent was obtained from the parents. Following insstitution of intravenous access, all neonates received atropine $(0.05$ to $0.1 \mathrm{mg})$ prior to induction of anaesthesia which was with thiopentone (4 to $6 \mathrm{mg} \cdot \mathrm{kg}^{-1}$ ) or propofol (2.5 to $\left.3.0 \mathrm{mg} \cdot \mathrm{kg}^{-1}\right)$ iv. Neuromuscular blockade was achieved with intermittent doses of vecuronium $\left(0.1 \mathrm{mg} \cdot \mathrm{kg}^{-1}\right)$. Routine intraoperative monitors were used including continuous ECG, pulse oximetry, non-invasive blood pressure measurement, end-tidal carbon dioxide monitoring, temperature, and either a precordial or ocsophageal stethoscope. Following anaesthetic induction a standard intravenous catheter was placed into the caudal epidural space. The infants were placed in the lateral decubitus position and sterile preparation carried out with betadine. After placement of the catheter through the sacrococcygeal membrane and into the epidural space, a $T$-piece which had been flushed with chloroprocaine $3 \%$ was attached to the catheter and secured in place with a transparent bio-occlusive dress- ing. The neonate was then lurned supine. The initial dose of chloroprocaine $3 \%$ included either 1.0 or 1.5 $\mathrm{ml} \cdot \mathrm{kg}^{-1}$ administered at three minute intervals in doses of $0.5 \mathrm{ml} \cdot \mathrm{kg}^{-1}$. Following the initial bolus dose, an infusion was started at a rate in $\mathrm{ml} \cdot \mathrm{kg}^{-1} \cdot \mathrm{hr}^{-1}$ equivalent to the initial bolus dose $\left(1.0\right.$ or $\left.1.5 \mathrm{ml} \cdot \mathrm{kg}^{-1} \cdot \mathrm{hr}^{-1}\right)$. Following the initial bolus dose, heart rate and blood pressure were recorded every two minutes and compared with baseline values. Maintenance anaesthesia consisted of either isoflurane $0.2 \%$ (expired concentration) in oxygen (40\%) and air or nitrous oxide (70\%) in oxygen. No opioids were administered at any time during the anaesthetic care. If the level of surgical anaesthesia were judged inadequate as demonstrated by an increase in heart rate or blood pressure in response to surgical stimulation, an additional bolus dose of chloroprocaine $3.0 \%\left(0.5 \mathrm{ml} \cdot \mathrm{kg}^{-1}\right)$ was administered and the infusion increased by $0.5 \mathrm{ml} \cdot \mathrm{kg}^{-1} \cdot \mathrm{hr}^{-1}$.

\section{Results}

The cohort for the study included 25 neonates ranging in age from 1 to 28 days (mean six days) and in weight from 2.2 to $4.9 \mathrm{~kg}$ (mean $3.3 \mathrm{~kg}$ ). The gestational age of the neonate varied from 30 to 41 weeks (mean 35.9 weeks). Associated medical conditions included renal dysplasia with an elevated blood urea nitrogen and creatinine in two patients, AV canal and Down's syndrome in one patient, and laryngotracheomalacia in one patient. The surgical procedures include exploratory laparotomy (ten neonates), closure of gastroschisis or omphalocoele (five neonates), colostomy (seven neonates), ileostomy takedown (two neonates), and bladder exstrophy repair (one neonate).

The caudal epidural space was identified in all neonates on either the first or second attempt. A standard 22 ga intravenous catheter was used in 21 neonates while a 24 ga catheter was used in four. The first three neonates of the study, who received an initial bolus dose of $1.0 \mathrm{ml} \cdot \mathrm{kg}^{-1}$ followed by an infusion of $1.0 \mathrm{ml} \cdot \mathrm{kg}^{-1}$. $\mathrm{hr}^{-1}$, required an additional bolus dose followed by an increase in the infusion to $1.5 \mathrm{ml} \cdot \mathrm{kg}^{-1} \cdot \mathrm{hr}^{-1}$. The remaining 22 received an initial bolus of $1.5 \mathrm{ml} \cdot \mathrm{kg}^{-1}$ followed by an infusion of $1.5 \mathrm{ml} \cdot \mathrm{kg}^{-1} \cdot \mathrm{hr}^{-1}$. This provided adequate intraoperative anaesthesia in all patients as evidenced by a lack of haemodynamic response to surgical incision. No neonate required more than isoflurane $0.2 \%$ or nitrous oxide $70 \%$ in oxygen. No episodes of haemodynamic instability (decreased blood pressure/bradycardia) related to the caudal epidural anaesthesia were noted.

Twenty-three of 25 neonates' tracheas were extubated in the operating room within ten minutes of the completion of the surgical procedure (time to extubation $=5.2$ 
$\pm 2.2 \mathrm{~min}$, mean $\pm \mathrm{SD}$ ). One neonate received a dose of vecuronium late in the intraoperative course and his trachea was extubated after transport back to the neonatal intensive care unit ( $20 \mathrm{~min}$ following completion of the surgical procedure). In one patient, tracheal intubation and mechanical ventilation were continued overnight due to concerns of the need for repeated surgical exploration due to compromised bowel perfusion. This patient met extubation criteria in the operating room immediately following the procedure, but the neonate's trachea was extubated the following morning. All neonates were observed for at least $48 \mathrm{hr}$ in the neonatal or paediatric intensive care unit. No episodes of postoperative apnoea or bradycardia were noted.

\section{Discussion}

Several options exist for providing surgical anaesthesia in neonates and infants including the inhalational anesthetic agents, synthetic opioids, and regional anaesthetic techniques. Advantages and disadvantages exist for all of these techniques. The inhalational agents can be easily titrated to achieve the desired level; however, in neonates especially, cardiovascular depression and alterations in cardiac output may occur. Additionally, it has been suggested that the inhalational anesthetics may not effectively blunt the post-surgical stress response and its deleterious physiologic effects. ${ }^{6}$ The synthetic opioids, on the other hand, effectively blunt the stress response, may improve postoperative outcome following surgery for congenital cardiac lesions, ${ }^{6}$ and provide relatively stable haemodynamic function even in preterm infants. However, when fentanyl is used in nconates as the major component of the anaesthetic, postoperative mechanical ventilation may be required. Additionally, the pharmacokinetic behaviour of fentanyl is extremely variable in infants and neonates, which further compounds the difficulties of predicting when ventilatory function will return to normal following an anaesthetic. This is particularly relevant following intra-abdominal procedures when fentanyl clearance is further decreased due to alterations in hepatic blood flow. ${ }^{7.8}$

The advantages of regional anaesthesia may include limiting the intraoperative requirements for inhalational/intravenous anaesthetic agents as well as effectively blunting the post-surgical stress response. Before starting this technique, our usual clinical practice for anaesthetic care for the majority of neonates undergoing these surgical procedures included a technique with fentanyl thereby necessitating postoperative mechanical ventilation. While we did not conduct a formal prospective comparison, our clinical experience suggests that the combination of caudal/general anaesthesia allows for earlier extubation, usually in the operating room, there- by eliminating the need and inherent risks of postoperative mechanical ventilation. Although we have used this technique in two patients with an omphalocoele, both of the defects were small $(<3 \mathrm{~cm})$ and closing them did not produce severe cardiorespiratory compromise. Due to the considerable alteration in cardiorespiratory function that may occur with closure of an omphalocoele, ${ }^{9}$ early extubation is not recommended in neonates with larger defects.

Studies in the adult population have demonstrated many benefits of regional anaesthesia especially in patients at high risk for postoperative cardiorespiratory dysfunction. These benefits include quicker postoperative recovery with earlier hospital discharge, decreased incidence of postoperative cardiovascular events, improved respiratory function, and limiting postoperative metabolic derangements. ${ }^{10-12}$ While information is limited in the paediatric population, caudal epidural analgesia has been shown to blunt the metabolic and endocrine stress response following lower abdominal surgery in children. ${ }^{5}$ Controlling this response may be particularly relevant in the neonatal population since Anand et al. have demonstrated that the stress response and its accompanying metabolic derangements occur even in preterm infants and in fact, is highest in patients with the highest morbidity and mortality. ${ }^{13}$ It remains to be determined which anaesthetic technique (regional anaesthesia or synthetic opioids) most effectively blunts the stress response and whether controlling the stress response is relevant to postoperative morbidity and mortality during non-cardiac surgical procedures.

Murrell et al. combined lumbar epidural blockade with general anaesthesia for various abdominal procedures in 14 infants age $I$ to 35 days as well as six former preterm infants. ${ }^{14}$ They found that the lumbar epidural administration of bupivacaine $0.25 \%$ provided excellent intraoperative surgical conditions while limiting the requirements for inhalational anaesthetic agents and eliminating the need for intravenous opioids. The tracheas of all patients were successfully extubated at the completion of the surgical procedure. The major difference in our current practice is that we prefer to use chloroprocaine for intraoperative anaesthesia. With caudal epidural administration, relatively larger doses are required to achieve the desired level of anaesthesia. Until recently, only local anaesthetics with long plasma half-lives such as lidocaine or bupivăcaine were commonly used for epidural anaesthesia in the paediatric population. The majority of reports have used doses in the range of 3 to $4 \mathrm{mg} \cdot \mathrm{kg}^{-1}$ of bupivacaine for single shot administration. Although these doses will not result in toxic serum concentrations following the initial dose, ${ }^{15}$ these may be reached if repeated doses are 
required. As the duration of surgical anaesthesia is generally a maximum of $90 \mathrm{~min}$ following the epidural administration of bupivacaine in neonates and infants, other agents may offer a decreased risk of toxicity when repeated dosing is required. Local anaesthetic toxicity may be a particular concern in neonates and infants as the pharmacokinetics of bupivacaine remain poorly understood in this age group. It is also our opinion, based on our experience with the use of chloroprocaine and bupivacaine for caudal anaesthesia instead of general anaesthesia during herniorrhaphy, ${ }^{4}$ that the degree of sensory block is more complete and the onset of action is more rapid with chloroprocaine $3 \%$ than with bupivacaine $0.25 \%$. The denser sensory block may explain why our intraoperative anaesthetic requirements isoflurane $0.2 \%$ or nitrous oxide $70 \%$ were lower than those described by Murrell et al. (isoflurane 1.0\%).

Henderson et al. were the first to report the use of caudal epidural chloroprocaine in neonates and infants. ${ }^{16}$ Their initial report included former preterm infants in whom the caudal epidural administration of chloroprocaine was used instead of general anaesthesia. Initial doses included $2 \mathrm{ml} \cdot \mathrm{kg}^{-1}$ followed by a continuous infusion of $2 \mathrm{ml} \cdot \mathrm{kg}^{-1} \cdot \mathrm{hr}^{-1}$. Due to its rapid metabolism by non-specific plasma esterases the risks of toxicity should be less than that of bupivacaine, even after repeated dosing. In the study of Henderson et al., plasma levels were zero in four patients and $0.5 \mathrm{mg} \cdot \mathrm{ml}^{-1}$ in the fifth. We initially started with doses of $1 \mathrm{ml} \cdot \mathrm{kg}^{-1}$ followed by a continuous infusion of $1 \mathrm{ml} \cdot \mathrm{kg}^{-1} \cdot \mathrm{hr}^{-1}$. When the first three neonates of our current study required a bolus dose and an increase in the infusion to $1.5 \mathrm{ml} \cdot \mathrm{kg}^{-1} \cdot \mathrm{hr}^{-1}$ to provide adequate surgical anaesthesia, we subsequently used the higher doses in the rest of our patients. A formal dose finding study was not conducted. It is possible that $1 \mathrm{ml} \cdot \mathrm{kg}^{-1} \cdot \mathrm{hr}^{-1}$ may be sufficient for some patients, depending on the surgical procedure and the height of epidural block that is required.

In summary, we have presented our initial experience with caudal epidural anaesthesia with chloroprocaine as an adjunct to general anaesthesia during intra-abdominal surgery in neonates. The advantages of this technique may include avoiding the use of parenteral opioids as well as limiting the intraoperative requirements for inhalational anaesthetic agents. In our experience, this practice allows for earlier tracheal extubation. Additionally, regionally anaesthetic techniques may effectively blunt the deleterious physiologic effects of the post-surgical stress response.

\section{References}

1 Payne KA, Hendrix MRG, Wade WJ. Caudal bupivacaine for postoperative analgesia in pediatric lower limb surgery. J Pediatr Surg 1993; 28: 155-7.

2 Dalens B, Hasnaoui $A$. Caudal anesthesia in pediatric surgery: success rate and adverse effects in 750 consecutive patients. Anesth Analg 1989; 68: 83-9.

3 Spear RM, Deshpande JK, Maxwell LG. Caudal anesthesia in the awake, high-risk infant. Anesthesiology 1988; 69: 407-9.

4 Tobias. ID, Lowe S, O'Dell N, Pietsch JB, Neblett WW III. Continuous regional anaesthesia in infants. Can $J$ Anaesth 1993; 40: 1065-8.

5 Nakamura T, Takasaki $M$. Metabolic and endocrine responses to surgery during caudal analgesia in children. Can J Anaesth 1991; 38: 969-73.

6 Anand K.IS, Hickey PR. Halothanc-morphine compared with high-dose sufentanil for anesthesia and postoperative analgesia in neonatal cardiac surgery. N Engl J Med 1992; 326: 1-9.

7 Davis PJ, Killian A, Stiller RL, Cook DR, Guthrie RD, Scierka AM. Pharmacokinetics of allentanil in newborn premature infants and older children. Devclopmental Pharmacology \& Therapeutics 1989; 13: 21-7.

8 Koehntop DE, Rodman JH, Brundage DM, Hegland $M G$, Buckley JJ. Pharmacokinetics of fentanyl in neonates. Anesth Analg 1986; 65: 227-32.

9 Yaster M, Buck JR, Dudgeon DL, et al. Hemodynamic effects of primary closure of omphalocele/gastroschisis in human newborns. Anesthesiology 1988; 69: 84-8.

10 Yeager MP, Glass DD, Neff RK, Brinck-Johnsen T. Epidural anesthesia and analgesia in high-risk surgical patients. Anesthesiology 1987; 66: 729-36.

11 Vedrinne $C$, Vedrinne $J M$, Guiraud $M$. Patricol $M C$, Bouletreau $P$. Nitrogen-sparing effect of epidural administration of local anesthetics in colon surgery. Ancsth Analg 1989; 69: 354-9.

12 Shuman RL, Peters RM. Epidural anesthesia following thoracotomy in patients with chronic obstructive airway disease. J Thorac Cardiovasc Surg 1976; 71: 82-8.

13 Anand KJS, Hansen DD, Hickey PR. Hormonal-metabolic stress responses in neonates undergoing cardiac surgery. Anesthesiology 1990; 73: 661-70.

14 Murrell D, Gibson PR, Cohen RC. Continuous epidural analgesia in newborn infants undergoing major surgery. J Pediatr Surg 1993; 28: 548-53.

15 Maziot JX, Denson DD. Samii K. Pharmacokinetics of bupivacaine following caudal anesthesia in infants. Anesthesiology 1988; 68: 387-91.

16 Henderson $K H$, Sethna $N F$, Berde $C B$. Continuous caudal anesthesia with 2-chloroprocaine for premature infants undergoing inguinal hernia repair. Anesthesiology 1991; 75: A916. 